\title{
CEREBRAL MUCORMYCOSIS
}

\author{
BY \\ F. KURREIN \\ From the Department of Pathology, the Royal Infirmary, Worcester
}

(RECEIVED FOR PUBLICATION DECEMBER 12, 1953)

The Mucoraceae are generally considered saprophytic, but since Cohnheim (1865) described two cases of pulmonary mycosis due to mucor a considerable number of infections of ear, lungs, and stomach by this fungus have been reported. Affections of the meninges and brain, however, are somewhat rare. After the paper of Paltauf (1885) no further reports appeared till Gregory, Golden, and Haymaker (1943) reviewed the literature and presented three cases of their own occurring in moribund diabetics. Subsequently LeCompte and Meissner (1947) and Wolf and Cowen (1949) added one case each. In the report of Hafström, Sjöqvist, and Henschen (1941) their diagnosis cannot be accepted from the illustrations or the description.

The case presented here differs from those previously reported, as the infection occurred in the absence of diabetes and without involvement of the orbit.

\section{Case Report}

M.R., a boy of 5 months, was admitted on November 25, 1952. He had been in all respects normal until three weeks before admission, when he had a mild upper respiratory infection as well as diarrhoea with blood and mucus in the stools. He appeared to respond favourably to treatment, but six days before admission he began to vomit. Frank haematuria was noticed the next day and puffiness of the face a day later. From then on the infant had difficulty and pain in passing progressively scantier amounts of urine. Three days before admission he had a convulsion affecting the right half of the body.

On admission he was pale and oedematous. His weight was $7 \mathrm{~kg}$., pulse 128 , respirations 40 , temperature $99.2^{\circ}$ F., blood pressure $105 / 75 \mathrm{~mm}$. of mercury. Physical signs were normal in the major systems. Haemoglobin was $6.8 \mathrm{~g}$. \%, and red blood cells $2,440,000$ per c.mm. Films showed anisocytosis and poikilocytosis, hypochromia and polychromasia, occasional nucleated red cells and myelocytes. The infant was Group A rhesus positive. The blood urea level was $340 \mathrm{mg}$. \%, and the blood cholesterol 180 mg. \%. The urine was acid with $780 \mathrm{mg}$. \% protein, and no reducing substance. The deposit contained numerous erythrocytes, leucocytes, and occasional granular casts.
Treatment for the first 24 hours was by oral fluids. As the anuria persisted the full Bull regime (Bull, Joekes, and Lowe, 1949), $350 \mathrm{ml}$. of peanut-oilglucose mixture given daily by pernasal intragastric drip, was begun on November 26 and continued till December 3. The output of urine during this period ranged from $10 \mathrm{ml}$. to $85 \mathrm{ml}$. per day. Investigations on November 28 showed $1,800 \mathrm{mg}$. \% urinary protein, $400 \mathrm{mg}$. \% blood urea, and haemoglobin $6.5 \mathrm{~g}$. \%. The next day $50 \mathrm{ml}$. of compatible packed red cells was transfused. As signs and symptoms of respiratory infection appeared, 250,000 units of penicillin daily were given intramuscularly. By December 2 urinary proteins were $840 \mathrm{mg}$. \% and the blood urea $410 \mathrm{mg}$. \%. Next day a brisk attack of diarrhoea caused severe dehydration necessitating a subcutaneous infusion of $300 \mathrm{ml}$. of Hartmian: solution. The pernasal intragastric drip was resumed on December 4, but, even with adequate doses of chloromycetin, the diarrhoea recurred on the next day, and $360 \mathrm{ml}$. of Hartman's solution was given intravenously. By December 8 marked oedema had appeared and that night respirations became rapid and deep. Blood urea was $488 \mathrm{mg}$. \%. On the morning of December 9 the infant passed three black stools and vomited altered blood. He died at 5.30 p.m. that day.

\section{Necropsy}

Necropsy was performed 21 hours after death. The body was that of an oedematous male infant.

The respiratory system showed some aspirated vomit in the trachea and the bronchi of the upper lobe of the right lung. The liver weighed $210 \mathrm{~g}$., and its cut surface revealed a firm, rather yellow, fatty parenchyma. The cardiovasular system was normal. The gall bladder, spleen, pancreas, and adrenals were macroscopically normal. Both kidneys appeared slightly enlarged (weight 65 g.) and showed numerous congested vessels on the surfaces. The capsules stripped easily, leaving smooth, pale subcapsular surfaces. Sections showed a normal cortico-medullary pattern except for numerous points of congestion. The rest of the genito-urinary tract was normal. Numerous punched-out erosions were present in the mucosa of the stomach, while the rest of the alimentary 


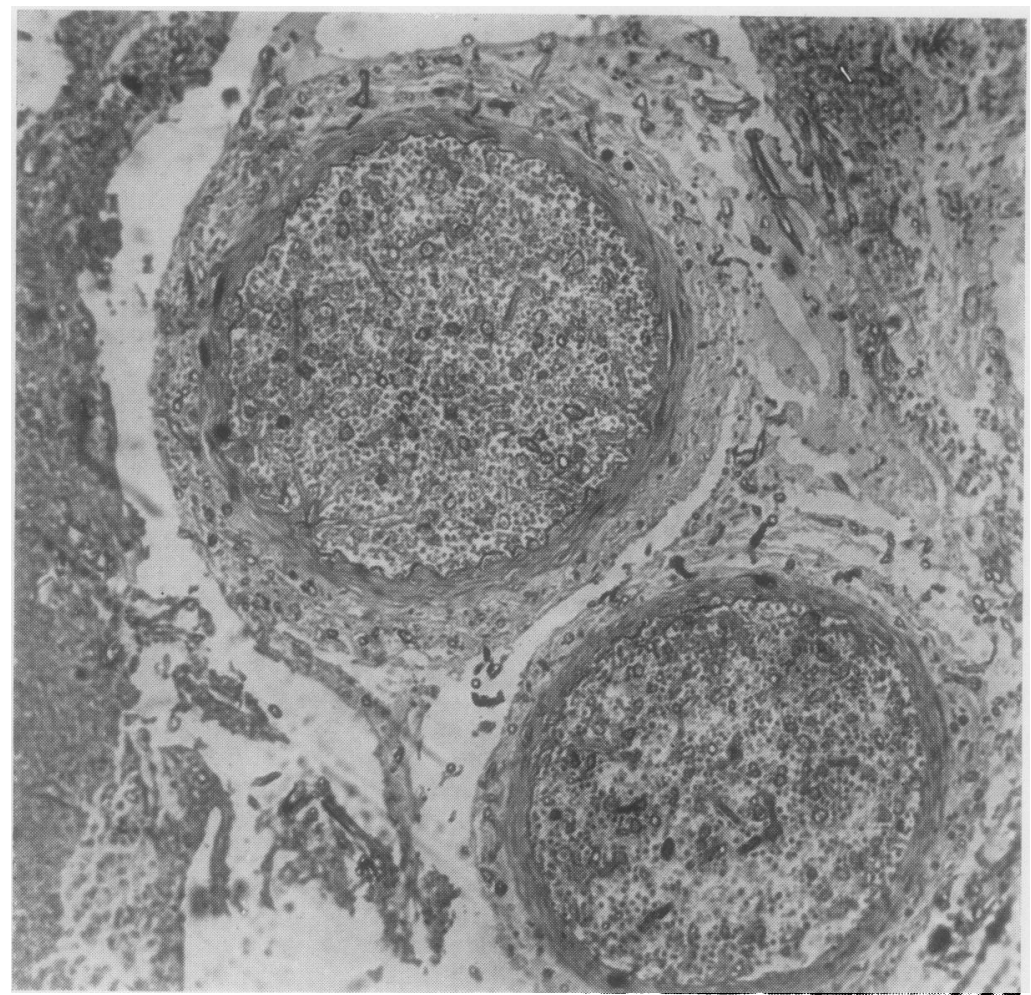

FIG. 1 (1534).-General appearance of the vessels and meninges. P.A.S. stain. $\times 48$. the orbital surface of the frontal lobe and accom- $\frac{\vec{F}}{\vec{F}}$ panying vessels in the sulci (Fig. 1). The exudate con- $\frac{}{0}$ sisted of a loose fibrin net- $\overline{\bar{\omega}}$ work enmeshing numerous $\mathbb{\nabla}$ erythrocytes and a variable number of granulocytes, क lymphocytes, and large $\overrightarrow{0}$ round cells. Varying de- $\overrightarrow{\vec{H}}$ grees of degeneration affec- $\stackrel{\omega}{\sigma}$ ted these cells. Much more $\overrightarrow{0}$ prominent than the cells? were considerable amounts iv of large, branching, non- $\vec{A}$ septate hyphae (Fig. 2). They were considered the $\frac{O}{2}$ agent responsible for the $\overrightarrow{-}$ tissue reaction. The hyphae $\vec{z}$ were found also among the muscle fibres of arterial $\overrightarrow{0}$ walls and in the lumina of $\rightarrow$ arteries and veins. In the arterial wall they appeared to penetrate in the ground substance between fibres, eventually lifting the internal elastic membrane off the muscle, stretching and finally rupturing it (Figs. 3 tract appeared normal but contained much altered blood. The skull and dura appeared normal. The orbital surface of the left frontal lobe showed a peculiar, pinkish brown, sharply demarcated area about $6 \times 4 \mathrm{~cm}$. As the significance of this was not realized, the brain was, as is our usual practice, fixed whole in formol-saline. The middle ears and orbits seemed normal.

\section{Histology}

Blocks taken from both kidneys and from the discoloured area of the brain were dehydrated in alcohols, cleared in benzene, and embedded in paraffin wax. Sections of the kidneys showed marked exudative and proliferative glomerulitis with the formation of epithelial crescents in many places.

Brain sections were stained by Harris's haematoxylin and eosin, Verhoeff's elastin and Van Gieson's mixture, the Gram-Weigert technique for fibrin, Mallory's phosphotungstic acid haematoxylin, Gram's stain, Ziehl-Neelsen, and by the periodic acid-Schiff technique.

The most striking feature was a thin layer of haemorrhagic exudate in the leptomeninges over and 4). Loose fibrin thrombi containing large amounts of mycelium and variable numbers of leucocytes filled the vascular lumina. Capillaries contained predominantly polymorphonuclear cell $\dot{0}$ collections without evidence of fibrin whether hyphae were present or not.

The grey matter adjoining the meningitic areas showed oedema, some cellular infiltration by round cells and occasional granulocytes. The latter were usually related to hyphae although more often the fungus was present without any cellular reaction (Fig. 5). No obvious lesions were seen in the white matter. Gliosis could not be demonstrated in relation to the fungus.

The mycelium stained well with haematoxylin and by the P.A.S. method ; it was Gram-negative and failed to retain carbol-fuchsin in the ZiehlNeelsen stain.

\section{Discussion}

The condition was not recognized at necropsy and no cultures were put up. Absolute proof of the identity of the fungus could not, therefore, be obtained. However, the appearance, and in particular the intravascular growth, compares closely 


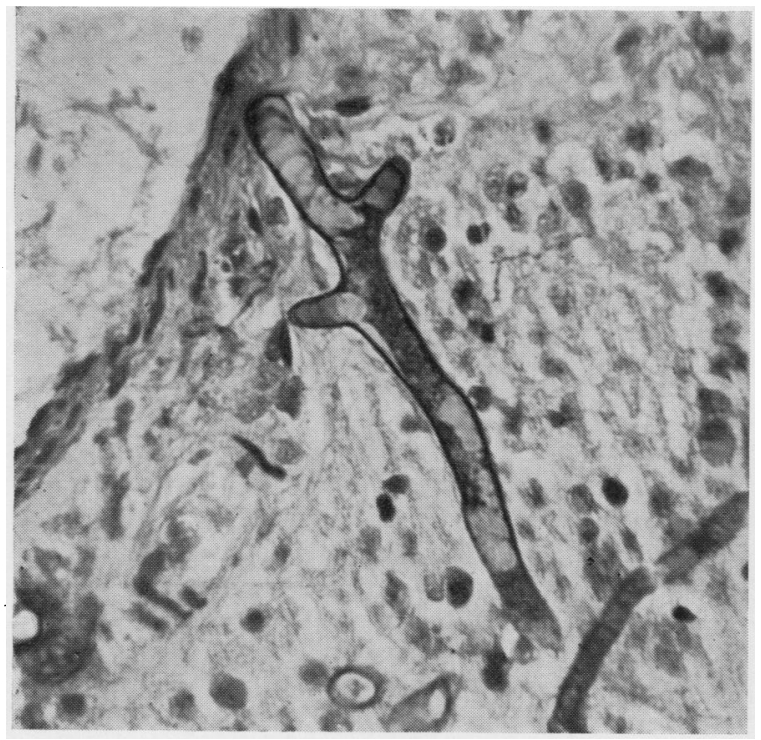

FIG. 2

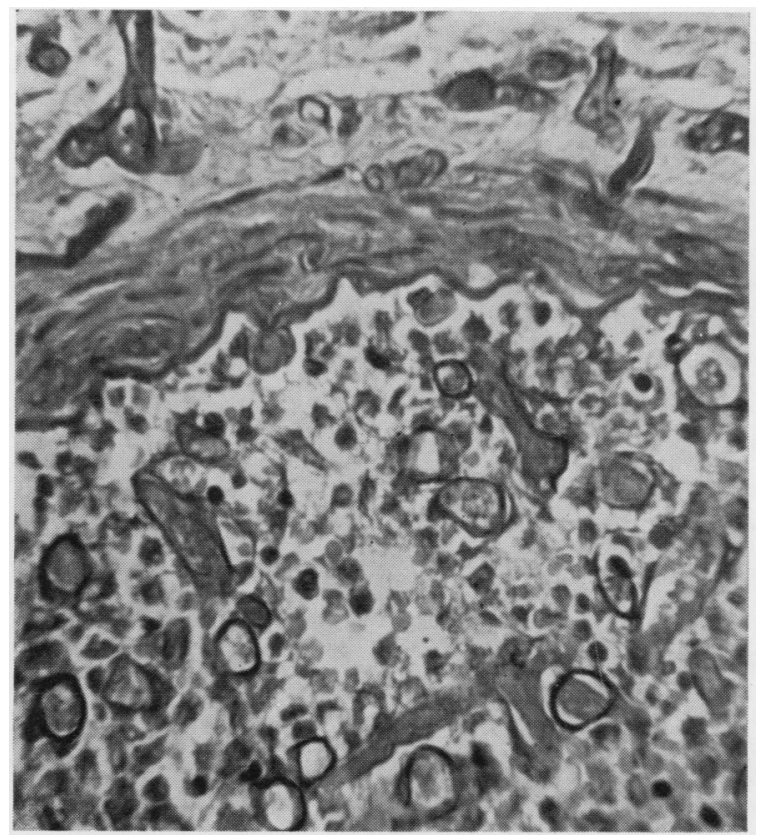

FIG. 3
FIG. 2 (1537).-Non-septate branching mycelium. Haematoxylin and eosin. $\times 192$.

FIG. I3 (1535). - Mycelium within and without an artery. P.A.S. stain. 192.

Fig. 4.-Another photomicrograph showing mycelium in an arterial wall with special reference to the internal elastic lumina.'

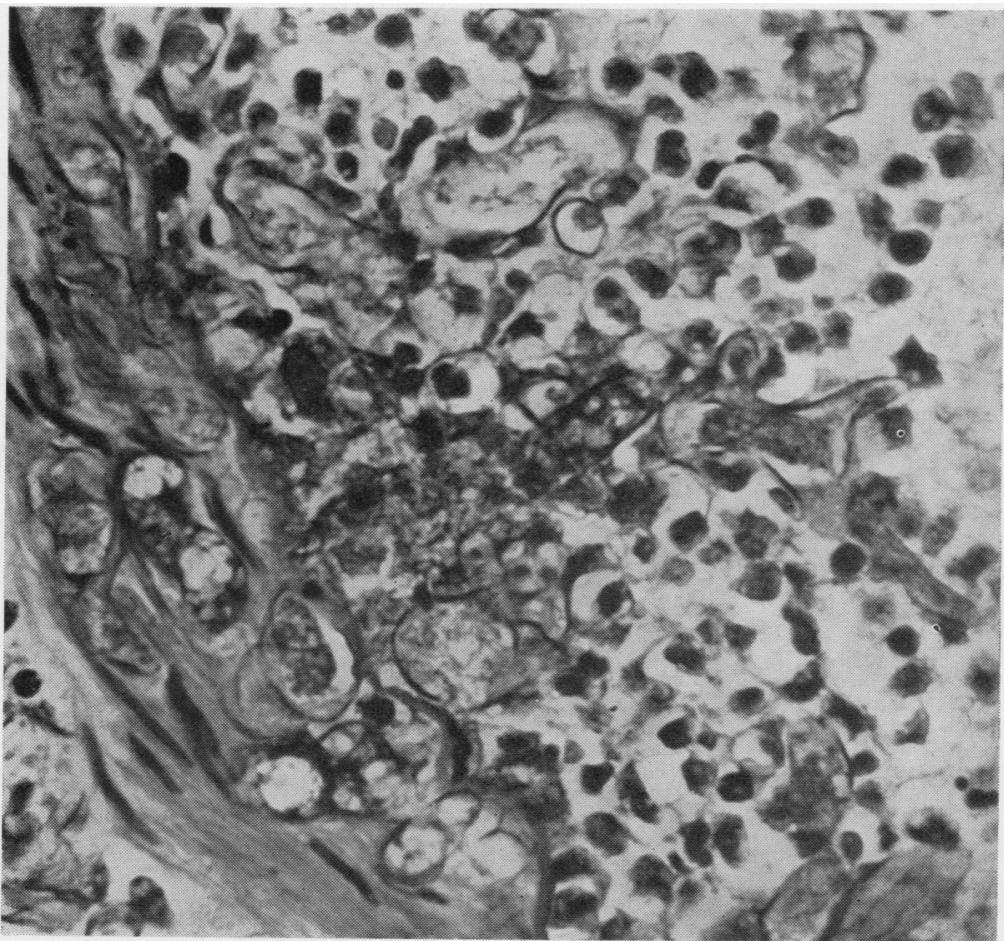

Fig. 4 


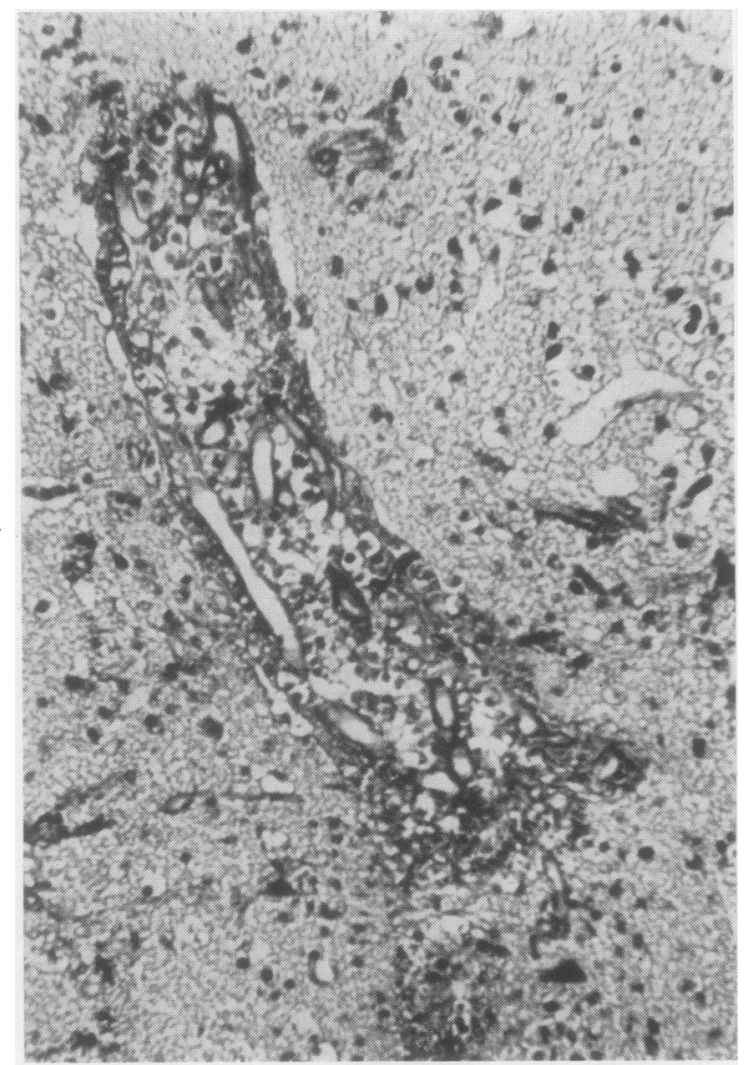

FIG. 5. (1540). - The relatively slight reaction around a fairly severely involved small vessel in cortex. Haematoxylin and eosin. $\times 150$.

with the descriptions and illustrations in the previous papers and in The Pathology of Tropical Diseases by Ash and Spitz (1945).
Sections were submitted to Dr. R. W. Riddell, of the Brompton Hospital, London, who reported a $\overrightarrow{\bar{F}}$ follows: "The nonsegmented and very wide mycelium is typical of the Mucoraceae."

It seems likely that the infection occurred $i \frac{\overline{\bar{w}}}{\text {. }}$ the terminal phase of uraemia and that the lon indwelling nasal tube of the intragastric drip was instrumental in introducing and spreading the fungus. In the absence of clinical orbital infece tion, the ethmoid, olfactory plate, or the nasal vein $\overline{\underline{s}}$ must be regarded as the most likely pathways.

\section{Summary}

A case of mucormycosis of the central nervous system is reported. It occurred in an infant aged 5 months dying in uraemia due to acute nephritis Unlike the previously reported cases, there was ne coexistent diabetes, and no frank invasion of the eye and orbit. As far as can be ascertained, this is only the seventh case of this condition to be. reported.

I wish to thank Professor D. S. Russell and DE R. W. Riddell for their advice and helpful criticismo I am indebted to Mr. J. G. Williamson, of the Birms ingham Children's Hospital, for the photographs. The sections were prepared by Mr. G. Haworth.

\section{REFERENCES}

Ash, J. E., and Spitz, S. (1945). Pathology of Tropical Disease p. 165. W. B. Saunders Co., Philadelphia and London.

Bull, G. M., Joekes, A. M., and Lowe, K. G. (1949). Lancet, 2, 229. Cohnheim, J. (1865). Virchows Arch. path Anat., 33, 157.

Gregory, J. E., Golden, A., and Haymaker, W.' (1943). Bull. Johm Hopk. Hosp., 73, 405.

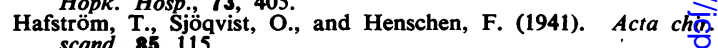
LeCompte, P. M., and Meissner, W. A. (1947). Amer. J. Path., 28, 673.

Paltauf, A. (1885). Virchows Arch. path. Anat., 102, 543.

Wolf, A., and Cowen, D. (1949). J. Neuropath, 8, 107. 